\title{
Antimicrobial Resistance Profile of Salmonella Isolates from Livestock
}

\author{
Sarah I. Umeh1*, Chika Paulinus Enwuru² \\ ${ }^{1}$ Department of Microbiology, Federal University of Technology, Owerri, Nigeria \\ ${ }^{2}$ Department of Medical Laboratory Sciences, Imo State College of Nursing and Health Sciences, Amaigbo, Nigeria \\ Email: ${ }^{*}$ elisarahumehsam@yahoo.co.uk
}

Received 21 October 2014; revised 19 November 2014; accepted 11 December 2014

Copyright (C) 2014 by authors and Scientific Research Publishing Inc.

This work is licensed under the Creative Commons Attribution International License (CC BY). http://creativecommons.org/licenses/by/4.0/

\section{(c) (i) Open Access}

\begin{abstract}
Food animals are important reservoirs of infectious pathogens. The use of antimicrobial drugs in food animals is a major source of selection of drug resistant pathogens. This study investigated a total of 1000 faecal samples of livestock and poultry between January 2012 and March 2013 to determine the prevalence rate of Salmonella species and their antimicrobial resistance profiles. Faecal samples of chicken, pig, cattle, goat and sheep (200 samples of each) were pre-enriched in Tetrathionate broth and Rappapport Vassiliadis R10 broth. The broth culture was subcultured on XLD agar and incubated. The isolates were identified by standard biochemical tests and confirmed by AP1 $20 \mathrm{E}$ test kit. Antimicrobial susceptibility was performed by disk diffusion method. The result showed that the prevalence of Salmonella spp. in all the samples was $21.8 \%$. Chicken faeces had the highest prevalence rate of $52.5 \%$ followed by pig faeces $(40 \%)$, cattle $(10 \%)$, goat $(4.5 \%)$ and sheep (2\%). The isolates have resistance profile ranging from 1 to 9 antimicrobial drugs. Tetracycline had the highest resistance $(81 \%)$ of all the isolates followed by Streptomycin (68\%). Gentamycin had the lowest resistance profile of $14 \%$. We conclude that Salmonella species have high prevalence rate in chicken and pig, but less in cattle, goat and sheep, and that most of the isolates are resistant to most commonly used antibiotics. Effort is needed to adopt measures to control the spread of multidrug resistant pathogens to humans. Care must be taken in the use of antibiotics in farm animals to reduce the selection of multidrug resistant strains.
\end{abstract}

\section{Keywords}

Antimicrobials, Faeces, Livestock, Multidrug Resistance, Salmonella

\section{Introduction}

The genus Salmonella, a gram negative oxidase-negative and lactose-negative motile bacillus is a member of the

*Corresponding author. 
family Enterobacteriaceae. Salmonella is a ubiquitous and hardy bacterium that can survive several weeks in a dry environment and several months in water. It has many pathogenic species and strains. Daniel Salmon, an American veterinarian first isolated Salmonella choleraesuis from pigs with hog cholera in 1884 [1] hence the name "Salmonella". Salmonella is an enteric pathogen and is the major cause of bacterial foodborne infections (Salmonella typhimurium and Salmonella enteritidis), enteric or typhoid fever (primarily Salmonella typhi and Salmonella paratyphi), bacteremia, endovascular infections, focal infection and enterocolitis (typically Salmonella typhimurium, Salmonella enteritidis, and Salmonella heidelberg).

The nomenclature and classification of Salmonella species have undergone several changes and rearrangements over the years. Traditionally, Salmonella species were named according to the Kaufmann-White typing system. This comprises different combinations of somatic, surface, and flagellar antigens (labelled as $\mathrm{O}$, Vi and $\mathrm{H}$ antigens respectively) [2] [3].

Recently, Salmonella species have serologically defined names appended as serovars or serotypes. Hence, Salmonella enterica was officially approved as the type species of the genus Salmonella. For instance, the current nomenclature of $S$. typhi is $S$. enterica serovar Typhi. To date, more than 2500 serovars of S. enterica have been described. Some serovars are host-specific and can reside in only one or a few animal species, for example, Salmonella Dublin in cattle; and Salmonella choleraesuis in pigs. When these particular serotypes cause disease in humans, it is often invasive and can be life-threatening. Others have a broad host range [4]. Typically, such strains cause gastroenteritis, which is often uncomplicated and does not need treatment, but can be severe in the young, the elderly and patients with weakened immunity.

According to Nouichi and Hamdi [5] food borne diseases often follow the consumption of contaminated food-stuffs especially from animal products such as meat from infected animals or carcasses contaminated with pathogenic bacteria as Salmonella spp., Staphylococcus aureus, Listeria monocytogenes, Campylobacter spp., and Escherichia coli O157: H7. Salmonella bacteria are widely distributed in domestic and wild animals. They are prevalent in food animals such as poultry, pigs and cattle, and in pets including cats, dogs, birds and reptiles such as turtles. Salmonella can pass through the entire food chain from animal feed, primary production, and all the way to households or food-service establishments and institutions.

Salmonellosis in humans is generally contracted through the consumption of contaminated food of animal origin such as eggs, meat, poultry and milk and green vegetables contaminated by faecal manure. Human cases occur where individuals have contact with infected animals, including pets. These infected animals often do not show signs of disease [6].

Since the beginning of the 1990s, Salmonella strains which are resistant to a range of antimicrobials have emerged and are now a serious public health concern. Salmonella has a widespread distribution in the environment and certain host factors make humans particularly susceptible to infection. Its increasing antimicrobial resistance, prevalence, virulence, and adaptability are a challenge worldwide.

Livestock and poultry producers rely on antibiotics to treat a host of diseases and infections as well as use low doses of antibiotics as growth promoters. Such treatments help promote the health and wellbeing of the animal. However, there are concerns about the potential influence of antibiotics on the development of bacterial resistant factors that limit antimicrobial efficacy [7].

In this study the prevalence rate of Salmonella species and antimicrobial resistance profile of Salmonella specie isolated from livestock faeces in selected farms in Owerri municipality was described and evaluated.

\section{Methodology}

\subsection{Sample Collection}

A total of 1000 fresh faecal samples comprising 200 each of cattle, pig, sheep, goat and chicken droppings were collected from different livestock farms in Owerri, Nigeria, using sterile containers.

\subsection{Culture and Isolation}

One gram of faecal sample each from cattle, sheep, goat, pig, and chicken were pre-enriched in Tetrathionate broth (TTB) containing $2 \%$ iodine-iodide solution for 24 hours at $37^{\circ} \mathrm{C}$ [8] [9]. This was followed by selective enrichment of $0.1 \mathrm{ml}$ of TTB culture in $10 \mathrm{ml}$ Rappapport Vassiliadis R10 broth (Difco) This was incubated for 24 hours at $41^{\circ} \mathrm{C} \pm 0.5^{\circ} \mathrm{C}$ [10] [11]. After incubation, a loopful of the enriched culture was sub-cultured onto 
XLD agar (made up of Yeast extract 3.0 g, L-lysine Hydrochloride 5.0 g, Xylose 3.75 g, Lactose 7.5 g, Sucrose $7.5 \mathrm{~g}$, Sodium desoxycholate $1.0 \mathrm{~g}$, Sodium chloride $5.0 \mathrm{~g}$, Sodium thiosulphate $6.8 \mathrm{~g}$, Ferric ammonium citrate $0.8 \mathrm{~g}$, Phenol red $0.08 \mathrm{~g}$ and Agar $12.5 \mathrm{~g}$ in one litre of deionized water; $\mathrm{pH}=7.4 \pm 0.2$ ) (Oxoid, UK) and incubated at $35^{\circ} \mathrm{C}$ for $18-24$ hours.

Red colonies with or without black centres growing on the XLD agar were picked, purified and gramstained. Biochemical tests for Salmonella were performed. The isolates were further confirmed as Salmonella spp. using AP1 20E test kit (Biomerioux, France).

\subsection{Antimicrobial Susceptibility Testing}

All isolates were subjected to antimicrobial susceptibility testing using disk diffusion method.

A bacterial lawn was prepared by transferring bacterial colonies to a glass tube containing $5 \mathrm{ml}$ sterile peptone water with a sterile inoculating loop.

The suspension was vortexed and visually matched with 0.5 MacFarland standard for turbidity [12].

Sterile cotton tipped swab was immersed in the suspension, excess fluid removed by rolling the swab on the upper part of the tube, and spread onto Mueller Hinton agar (Oxoid, UK) to obtain a semi-confluent growth.

Disks impregnated with predetermined amounts of antibiotics were dispensed onto the bacterial lawn and the plates were incubated for $18-24$ hours at $35^{\circ} \mathrm{C}$.

After the incubation, the diameter of the inhibition zones were measured and interpreted as sensitive or resistant using the criteria described by the Clinical and Laboratory Standards Institute [13].

The antibiotics used include:

Ampicillin $25 \mu \mathrm{g}$, Amoxicillin $25 \mu \mathrm{g}$, Augmentin $30 \mu \mathrm{g}$, Chloramphenicol $30 \mu \mathrm{g}$, Streptomycin $25 \mu \mathrm{g}$, Tetracycline $25 \mu \mathrm{g}$, Cephalothin $30 \mu \mathrm{g}$, Gentamycin $10 \mu \mathrm{g}$, Ciprofloxacin $5 \mu \mathrm{g}$, Sulfamethoxazole $25 \mu \mathrm{g}$, Nalidixic acid $30 \mu \mathrm{g}$.

\section{Results}

Out of the total of 1000 samples examined, 218 (21.8\%) yielded positive cultures for Salmonella species. Chicken faeces yielded the highest number of Salmonella isolates of 105 (52.5\% of the chicken faecal samples inoculated) while sheep faeces yielded the lowest (2\%, ieonly 4 isolates out of 200 samples: Figure 1).

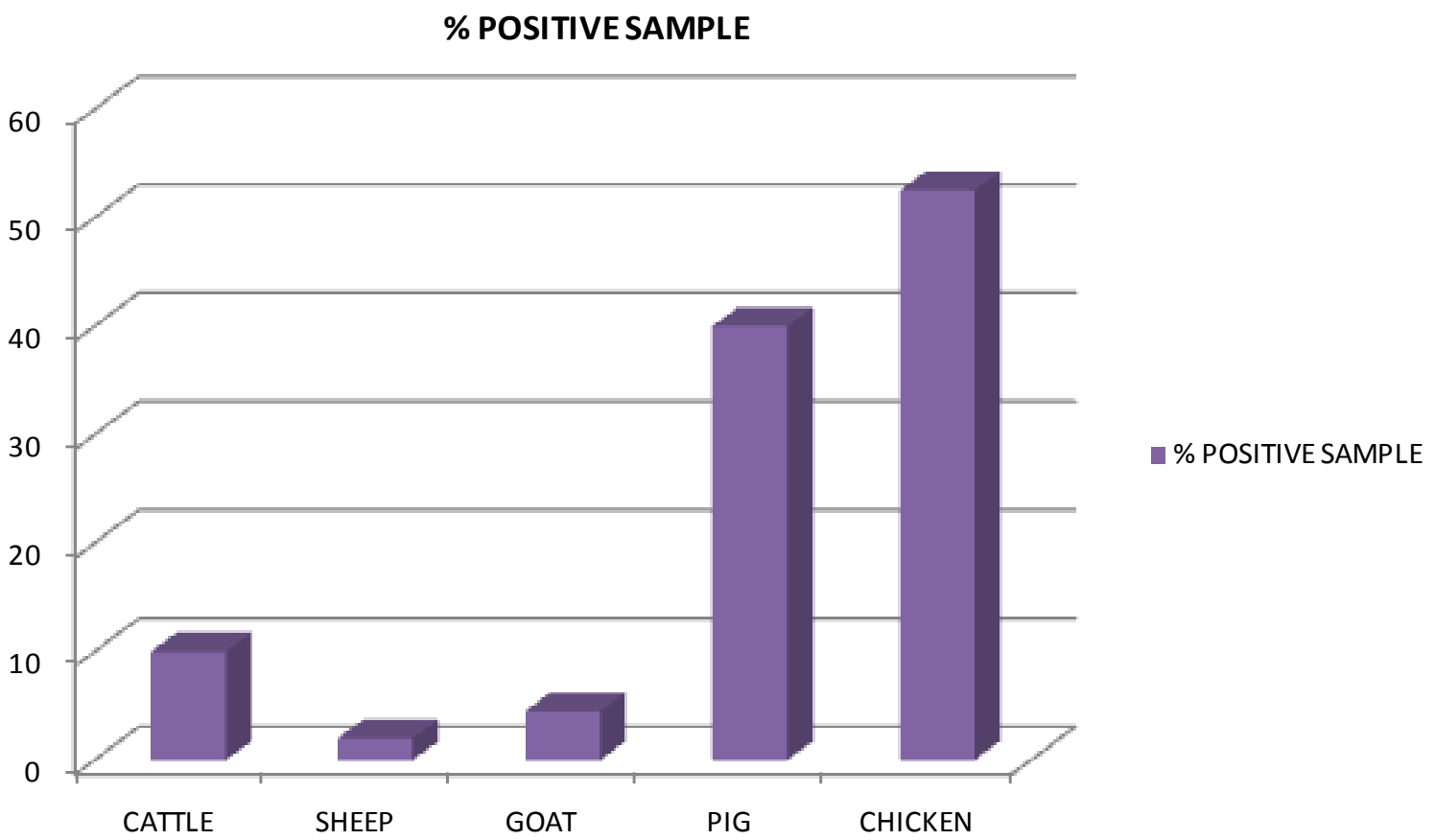

Figure 1. Percentage positive samples from each faecal sample. $\mathrm{X}$-axis = source of livestock faeces; $\mathrm{Y}$-axis $=\%$ positive sample. 
Isolates from chicken, cattle and pig show highest resistance to most antimicrobial drugs (Table 1). Isolates from chicken show the highest resistance to Tetracycline followed by resistance to Nalidixic acid, Sulphamethoxazole, Streptomycin, Ampicillin and Cephalothin in that order. Isolates from pig follow similar pattern (Figure 2).

Tetracycline has the highest number of total resistant isolates from all the specimens put together. This was followed by Streptomycin and Nalidixic acid respectively. Gentamycin and ciprofloxacin have the least resistant isolates (Figure 3).

\section{Discussion}

This study has revealed that farm animals habour a good number of Salmonella species (21.8\% of all the samples

Table 1. Multidrug resistance pattern of Salmonella isolates from different specimens.

\begin{tabular}{ccccccc}
\hline & Cattle $(\mathrm{n}=20)$ & Sheep $(\mathrm{n}=4)$ & Goat $(\mathrm{n}=9)$ & Chicken $(\mathrm{n}=105)$ & Pig $(\mathrm{n}=80)$ & Total $(\mathrm{n}=218)$ \\
\hline Ampicillin & $15(75 \%)$ & $1(25 \%)$ & $2(22 \%)$ & $70(67 \%)$ & $40(50)$ & $128(59 \%)$ \\
Amoxicillin & $3(15 \%)$ & $0(0 \%)$ & $1(11 \%)$ & $20(19 \%)$ & $15(19 \%)$ & $39(18 \%)$ \\
Augmentin & $7(35 \%)$ & $0(0 \%)$ & $1(11 \%)$ & $40(38 \%)$ & $20(25 \%)$ & $68(31 \%)$ \\
Chloramphenicol & $15(75 \%)$ & $1(25 \%)$ & $2(22 \%)$ & $75(71 \%)$ & $45(56 \%)$ & $138(63 \%)$ \\
Streptomycin & $15(75 \%)$ & $1(25 \%)$ & $2(22 \%)$ & $80(76 \%)$ & $50(62 \%)$ & $148(68 \%)$ \\
Tetracycline & $17(85 \%)$ & $1(25 \%)$ & $4(44 \%)$ & $95(90 \%)$ & $60(75 \%)$ & $177(81 \%)$ \\
Cephalothin & $10(50 \%)$ & $0(0 \%)$ & $2(22 \%)$ & $70(67 \%)$ & $40(50 \%)$ & $122(56 \%)$ \\
Gentamycin & $3(15 \%)$ & $0(0 \%)$ & $1(11 \%)$ & $14(13 \%)$ & $13(16 \%)$ & $31(14 \%)$ \\
Ciprofloxacin & $15(75 \%)$ & $0(0 \%)$ & $1(11 \%)$ & $10(9.5 \%)$ & $10(13 \%)$ & $36(17 \%)$ \\
Sulfamethoxazole & $10(50 \%)$ & $0(0 \%)$ & $2(22 \%)$ & $75(71 \%)$ & $45(56 \%)$ & $132(61 \%)$ \\
Nalidixic acid & $15(75 \%)$ & $1(25 \%)$ & $2(22 \%)$ & $80(76 \%)$ & $50(62 \%)$ & $143(66 \%)$ \\
\hline
\end{tabular}

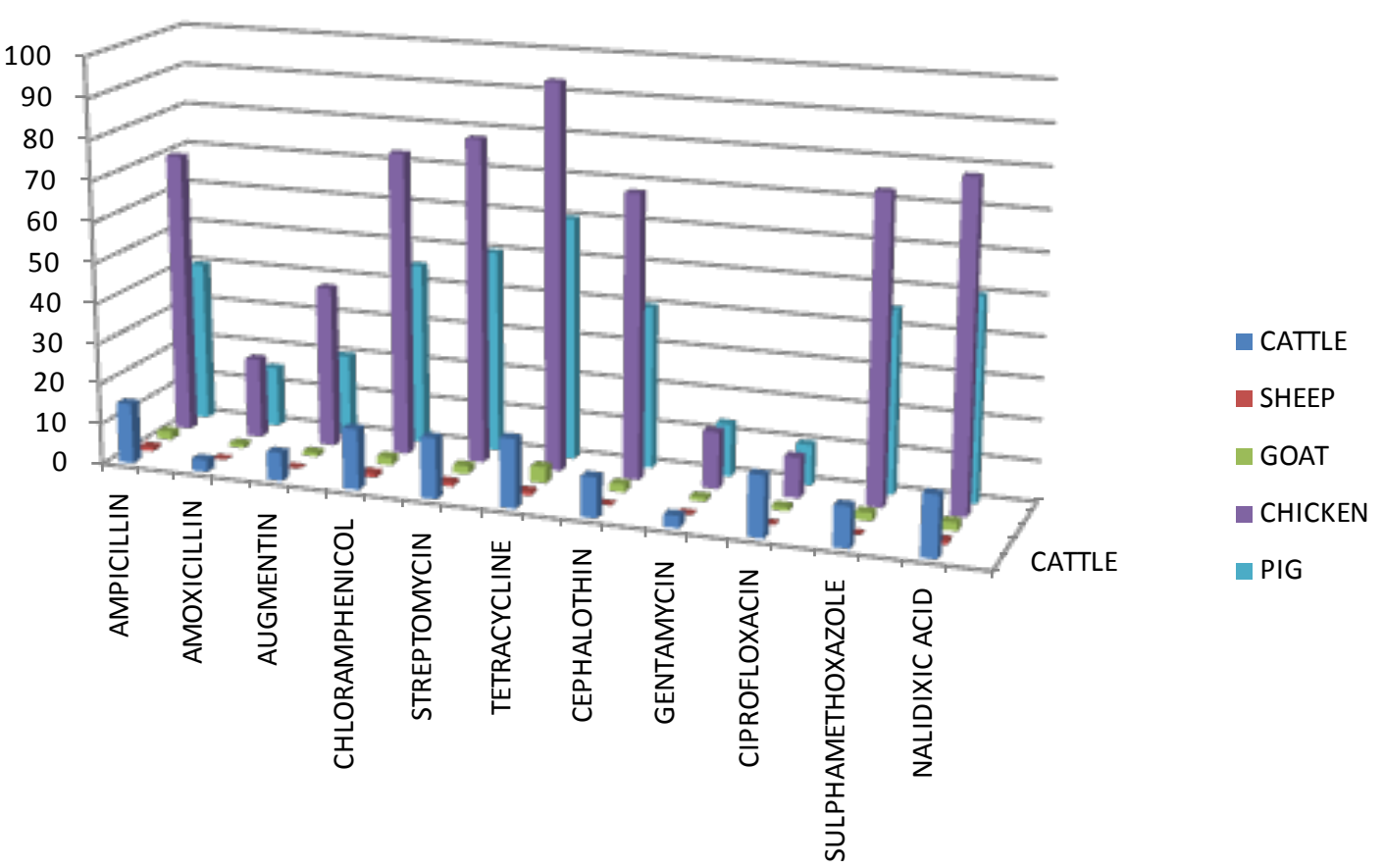

Figure 2. Comparison of number of resistant isolates from each live stock faeces. X-axis = antibiotics; Y-axis = Number of resistant isolates. 


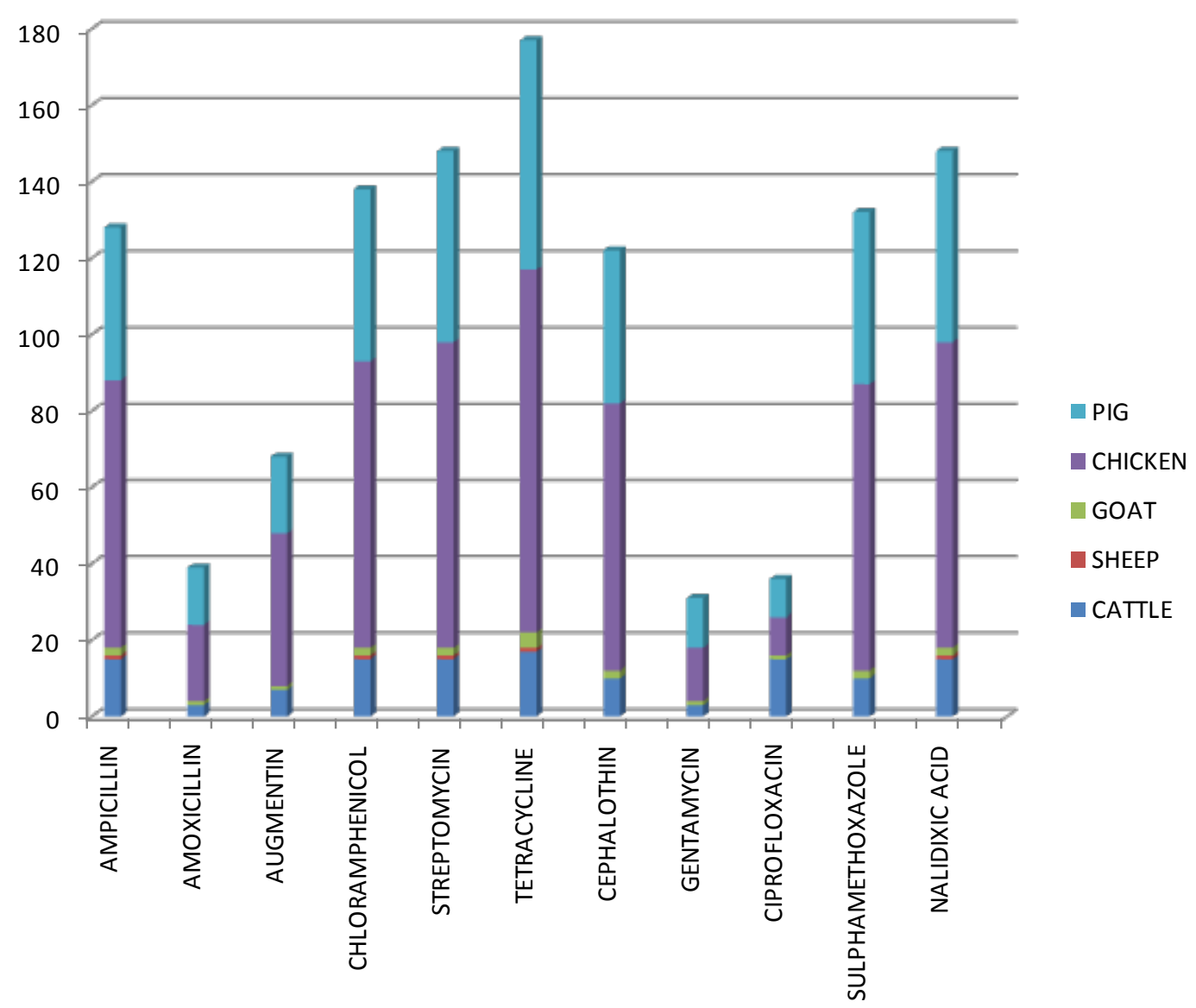

Figure 3. Contribution of each group of isolates to the total number resistant to each antimicrobial drug. $\mathrm{X}$-axis = antibiotics; $\mathrm{Y}$-axis $=$ cumulative resistant isolates

yielded Salmonella spp.). The largest number of Salmonella was isolated from chicken faeces followed by pig faeces, while sheep and goat faeces yielded the least. A number of studies have reported similar high Salmonella prevalence in farm animals usually slaughtered for food. Kishima et al. [14] reported the isolation of 172 strains of Salmonella from 218 pig farms in Japan. In Australia, Duffy et al. [15] reported 46.3\% Salmonella species isolation from the faeces of goat. Asseta Kagambega et al. [16] in Bukina Faso reported isolation of salmonella from $52 \%$ cattle faeces, $55 \%$ chicken faeces and $16 \%$ swine faeces. In Belgium, Botteldoorm et al. [17] reported $37 \%$ Salmonella prevalence in pig faeces. However, a few low prevalence rates of Salmonella have been reported by some researchers. In Ethiopia, Anbessa Dabassa et al. [18] isolated Salmonella from as low as 4.4\% cattle and sheep faeces but none from goat faeces. Alao et al. [19] reported only 14\% Salmonella isolation from goat and cattle faeces in Sango-Otta, Nigeria. Most of these studies reveal higher prevalence of Salmonella in chicken than in other farm animals which corresponds to our findings in this study. According to Asseta Kagambega et al. [16], the rate of Salmonella carriage in chicken is higher than the rate in cattle. But he points out that the rate of Salmonella isolation from these animal faeces may depend on the isolation methodology and the type of animal husbandry practiced in that country.

The administration of antimicrobial agents in animal production creates selection pressure that favours the survival of antibiotic resistant pathogens [20]. Resistance of Salmonella to commonly used antimicrobials is increasing both in veterinary and public health sectors and has emerged as a global problem. These animals are important reservoirs of antimicrobial resistant organisms. If resistant organisms are common in animals, the chances that they will be transmitted to humans are more likely since they are sources of food. Duffy et al. [15] has pointed out that goat meat is a potential source of Salmonella serovars associated with human disease. In this study, most Salmonella isolates show marked resistance to 1 - 9 of the 12 antimicrobial drugs used. Majority were resistant to Tetracycline, Ampicillin, Streptomycin, Chloramphenicol etc. These are the drugs widely used 
in the treatment of human systemic salmonellosis [21]. A similar study in Alberta, Canada indicates high resistance of Salmonella from food and food animals to Ampicillin, Streptomycin, Sulphamethoxazole and Tetracycline [22]. In Ethiopia, resistance pattern of Salmonella isolates from chicken indicates large proportions of strains resistant to a variety of drugs [23]. Also in a study in Alberta swine farms, highest frequencies of resistance were observed for chloramphenicol, Ampicillin, Kanamycin, Sulphamethoxazole, Streptomycin and Tetracycline [24]. Dabassa et al. [18] further reports that Salmonella isolates from cattle and sheep faeces show multidrug resistance to Ampicillin, Nalidixic acid, Streptomycin, Tetracycline and Chloramphenicol from which he concludes that foodstuffs particularly beef, chevon and mutton parts could be a potential vehicle for food borne infections. Furthermore, our study reports low resistance of the isolates to Ciprofloxacin and Gentamycin. Dabassa et al. [18] had earlier reported zero resistance of Salmonella isolates to the two drugs in Ethiopia.

Antimicrobial drug over use in animal agriculture is contributing to human public health problems [20] [24]. Microbial studies show that antimicrobial drug resistance from farm animals not only infect humans but may transfer the resistance to other bacteria that colonize the animal and human gut by mechanisms of gene (plasmid) transfer, thus serving as a prelude to severe risk of health crisis. This study only investigated "within farm" carriage of Salmonella. The major point to note here is that of selection of resistant strains of pathogens by the use of antibiotics for treatment of infected animals and for growth enhancement. Another important point is that of lateral spread of the drug resistant pathogens from an infected animal to the others within the farms. Thirdly the transfer of the pathogens from the infected animals to humans (farm workers) by direct contact with infected animal faeces and other body fluid, and from infected animals to other meat and meat products at slaughter houses and distribution points [15] [16] [25] [26]. Furthermore, the use of untreated animal dung for manure provides another rout of transfer of multidrug resistant pathogens to other food products such as vegetables and fruits that may be consumed raw or with insufficient cooking. The environment also gets contaminated with faecal pathogens in areas where farm animals are allowed to roam about and graze in open fields [16].

\section{Conclusion and Recommendations}

Our study has revealed high prevalence of Salmonella species in chicken and pig, and less prevalence in cattle, goat and sheep. We have further discovered that most of the isolates were resistant to most commonly used antibiotics for treatment of the infections. Effort is needed to adopt measures that will prevent the spread of these multidrug resistant pathogens to humans. Serious environmental hygiene and strict infection control measures must be adopted both in the treatment and disposal of animal dungs and at abattoirs to prevent contamination of the food chain. Use of untreated animal dung for manure should be discouraged. Care must be taken in the use of antibiotics in asymptomatic animals to reduce the selection of multidrug resistant strains. Authorities in Agriculture and Veterinary Medicine are advised to formulate code of conducts in this regard and ensure certain restrictions as it is done in the developed countries [25]. The public should be properly enlightened on the dangers of eating raw or insufficiently cooked food to forestall acquisition of these pathogens. Further studies are required to identify the particular strains of Salmonella haboured by the farm animals and the level of risks they pose to the public.

\section{References}

[1] Threlfall, E.J., Frost, J.A., Ward, L.R. and Rowe, B. (1996) Increasing Spectrum of Resistance in Multiresistant Salmonella typhimurium. The Lancet, 347, 1053-1054. http://dx.doi.org/10.1016/S0140-6736(96)90199-3

[2] Hald, T., Wegener, H.C. and Jørgensen, B.B., Eds. (1997) Annual Report on Zoonoses in Denmark. Danish Zoonosis Centre, Copenhagen, 1998.

[3] Callow, B.R. (1959) A New Phage-Typing Scheme for Salmonella typhimurium. Journal of Hygiene (Lond), 57, 346359. http://dx.doi.org/10.1017/S0022172400020209

[4] Anderson, E.S., Ward, L.R., Saxe, M.J. and de Sa, J.D.H. (1977) Bacteriophage-Typing Designations of Salmonella typhimurium. Journal of Hygiene (Lond), 78, 297-300. http://dx.doi.org/10.1017/S0022172400056187

[5] Nouichi, S. and Hamdi, T.M. (2009) Superficial Bacterial Contamination of Ovine and Bovine Carcasses at El-Harrach Slaughterhouse (Algeria). European Journal of Scientific Research, 38, 474-485.

[6] WHO (2013) Fact Sheet No. 139. Food Safety Department WHO/Geneva.

[7] Levy, S.B. (1987) Antibiotic Use for Growth Promotion in Animals, Ecologic and Public Health Consequences. Journal of Food Protection, 50, 616-620. 
[8] United States Pharmacopoeia (2005) Tetrathionate Broth. USP 28.

[9] American Public Health Association (1998) Standard Methods for the Examination of Water and Wastewater. 20th Edition, APHA Inc, Washington DC.

[10] Rappaport, F., Konforti, N. and Navon, B. (1956) A New Enrichment Medium for Certain Salmonellae. Journal of Clinical Pathology, 9, 261-266.

[11] Vassiliadis, P., Trichopoulos, D., Kalandidi, A. and Xirouchaki, E. (1978) Isolation of Salmonellae from Sewage with a New Procedure of Enrichment. Journal of Applied Bacteriology, 44, 233-239. http://dx.doi.org/10.1111/j.1365-2672.1978.tb00795.x

[12] National Committee for Clinical Laboratory Standards (2003) Approved Standard: M2-A8. Performance Standards for Antimicrobial Disk Susceptibility Tests, 8th Edition, National Committee for Clinical Laboratory Standards, Wayne, Pa.

[13] CLSI (2005) Performance Standards for Antimicrobial Susceptibility Testing. Fifteenth Informational Supplement, M100-S15, Clinical and Laboratory Standards Institute, Wayne.

[14] Kishima, M., Uchida, I., Namimatsu, T., Osumi, T., Takahashi, S., Tanaka, K., Aoki, H., Matsuura, K. and Yamamoto, K. (2008) Nationwide Surveillance of Salmonella in the Faeces of Pigs in Japan. Zoonosis Public Health, 55, $139-144$. http://dx.doi.org/10.1111/j.1863-2378.2007.01105.x

[15] Duffy, L., Barlow, R., Fegan, N. and Vanderlinde, P. (2009) Prevalence and Serotypes of Salmonella Associated with Goats at Two Australian Abattoirs. Letters in Applied Microbiology, 48, 193-197. http://dx.doi.org/10.1111/j.1472-765X.2008.02501.x

[16] Kagambèga, A., Lienemann, T., Aulu, L., Traoré, A.S., Barro, N., Siitonen, A. and Haukka, K. (2013) Prevalence and Characterization of Salmonella entericafrom the Feces of Cattle, Poultry, Swine and Hedgehogs in Burkina Faso and Their Comparison to Human Salmonella Isolates. BMC Microbiology, 13, 253. http://dx.doi.org/10.1186/1471-2180-13-253

[17] Botteldoorn, N., Heyndrickx, M., Rijpens, N., Grijspeerdt, K. and Herman, L. (2003) Salmonella on Pig Carcasses: Positive Pigs and Cross Contamination in the Slaughterhouse. Journal of Applied Microbiology, 95, 891-903. http://dx.doi.org/10.1046/j.1365-2672.2003.02042.x

[18] Dabassa, A. and Bacha, K. (2012) The Prevalence and Antibiogram of Salmonella and Shigella Isolated from Abattoir, Jimma Town, South West Ethiopia. International Journal of Pharmaceutical and Biological Research, 3, 143-148.

[19] Alao, F., Kester, C., Gbagba, B. and Fakilede, F. (2012) Comparison of Prevalence and Antimicrobial Sensitivity of Salmonella typhimurium in Apparently Healthy Cattle and Goat in Sango-Ota, Nigeria. The Internet Journal of Microbiology, 10. https://ispub.com/IJMB/10/2/14221

[20] Fey, P.D., Safranek, T.J., Rupp, M.E., Dunne, E.F., Ribot, E., Iwen, P.C., Bradford, P.A., Angulo, F.J. and Hinrichs, S.H. (2000) Ceftriaxone-Resistant Salmonella Infection Acquired by a Child from Cattle. The New England Journal of Medicine, 342, 1242-1249. http://dx.doi.org/10.1056/NEJM200004273421703

[21] D’Aust, J.Y., Swell, A.M., Daley, E. and Grec, O. (1999) Antibiotic Resistance of Agricultural and Food Borne Salmonella Isolates in Canada: 1986-1989. Journal of Food Protection, 55, 428-434.

[22] Johnson J.M., Rajic, A. and McMullen, L.M. (2005) Antimicrobial Resistance of Selected Salmonella Isolates from Food Animals and Food in Alberta, Canada. Canadian Veterinary Journal, 46, 141-146.

[23] Molla, B.A., Mesfin, A. and Alemayehu, D. (2003) Multiple Antimicrobial Resistant Salmonella Serotypes Isolated from Chicken Carcass and Giblets in Debre-Zeit and Adis Ababa, Ethiopia. Ethiopian Journal of Health Development, 17, 113-149.

[24] Rajic, A., McFall, M.E., Deckert, A.E., Reid-Smith, R., Mannien, K., Poppe, C., Dewey, E.C. and McEwen, S.A. (2004) Antimicrobial Resistance of Salmonella Isolated from Finishing Swine and Environment of 60 Alberta Swine. Veterinary Microbiology, 104, 189-196. http://dx.doi.org/10.1016/j.vetmic.2004.09.013

[25] John Threlfall, E. (2002) Antimicrobial Drug Resistance in Salmonella: Problems and Perspectives in Food- and Water-Borne Infections. FEMS Microbiology Reviews, 26, 141-148. http://dx.doi.org/10.1111/j.1574-6976.2002.tb00606.x

[26] Pires, A.F., Funk, J.A., Lim, A. and Bolin, S.R. (2013) Enumeration of Salmonella in Feces of Naturally Infected Pigs. Foodborne Pathogens and Disease, 10, 933-937. http://dx.doi.org/10.1089/fpd.2013.1547 
Scientific Research Publishing (SCIRP) is one of the largest Open Access journal publishers. It is currently publishing more than 200 open access, online, peer-reviewed journals covering a wide range of academic disciplines. SCIRP serves the worldwide academic communities and contributes to the progress and application of science with its publication.

Other selected journals from SCIRP are listed as below. Submit your manuscript to us via either submit@scirp.org or Online Submission Portal.
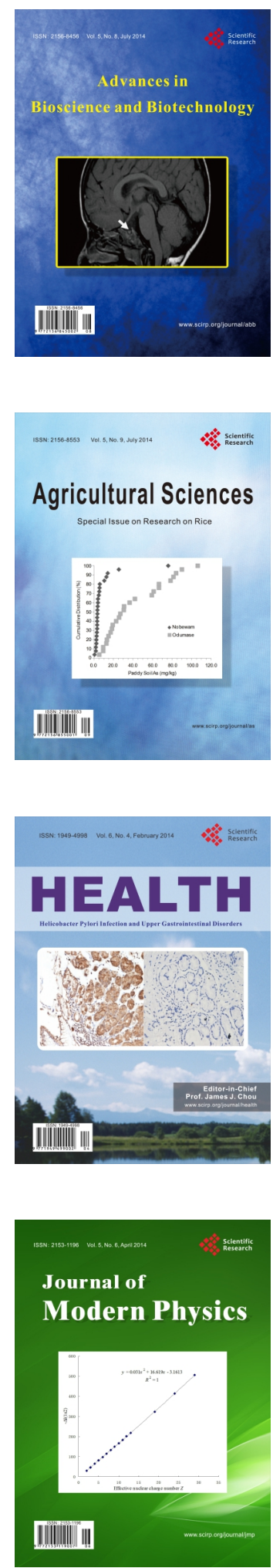
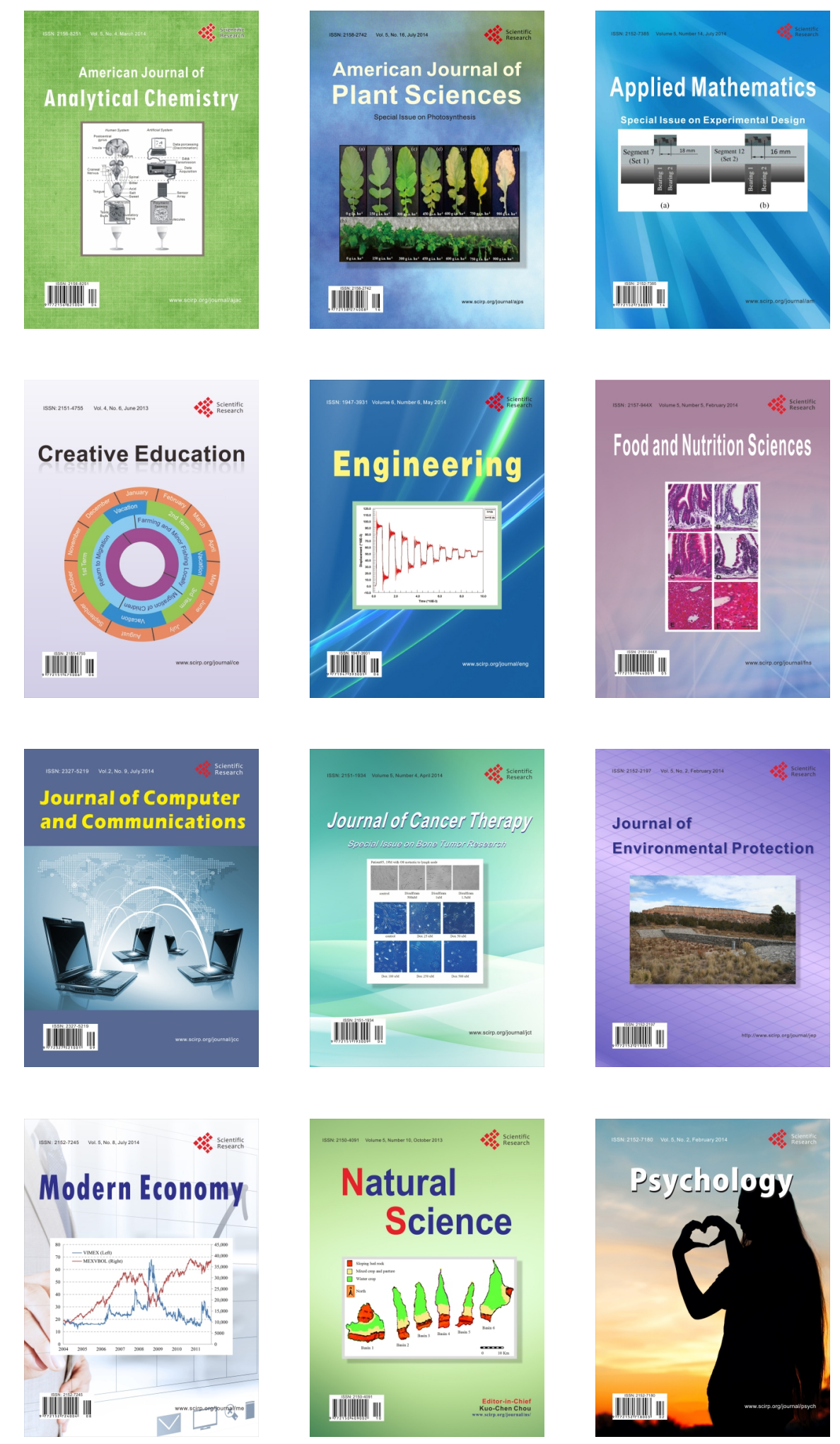